\title{
Developing SoTL through Organized Scholarship Institutes
}

\section{ABSTRACT}

The need to further integrate SoTL into college and university cultures has been discussed relatively frequently in recent teaching and learning literature. While a number of useful strategies to assist in this task have been advanced, one especially promising suggestion is the development of organized, institutionallyrecognized scholarship institutes. Centres or units of this sort have been created at higher education institutions in a number of countries, but little published information currently exists about the design of these institutes or the experiences of individuals affiliated with them. To that end, the present study sought to examine the perceived benefits, challenges and design features of teaching and learning scholarship institutes at research-intensive universities worldwide. A website scan and a survey of individuals affiliated with these units were used to collect qualitative and quantitative data of relevance to the research questions. Based on the findings, and on ideas from the existing research institute and scholarship of teaching and learning literatures, a series of recommendations for individuals and campuses interested in developing effective SoTL institutes are provided.

\section{KEYWORDS}

institutional integration, SoTL institutes, community, interdisciplinarity, professional development for SoTL

In recent years, the need to increase the institutional integration and impact of teaching and learning scholarship has been widely discussed (e.g., Ginsberg \& Bernstein, 2011; Williams et al., 2013). While—as Hutchings, Huber, and Ciccone (2011) point out—-the SoTL movement "has made great progress, in many settings it remains a special initiative $[\ldots]$ as yet only unevenly woven into the mainstream of academic life" (p.1). In order to fully meet its potential to enhance student learning, however, SoTL must be tightly interwoven into institutional fabrics, such that its findings inform teaching and learning practices in widespread and meaningful ways. This article reports the findings of research designed to assist in such integration.

The challenges attached to integrating SoTL more fully into institutional cultures are many, ranging from confusion about what SoTL is (Boshier, 2009) to heavy academic workloads (Brew, 2010) that can dissuade faculty from conducting teaching and learning scholarship or even reading it. The undervaluing of teaching and of SoTL must also be 
navigated (Chalmers, 2011; Walker, Baepler, \& Cohen, 2008), insofar as it too decreases the likelihood that SoTL will be undertaken or applied, and leaves many scholars who do conduct such work feeling isolated within their departments and/or institutions (Mighty, 2013). Existing literature also describes the difficulties of becoming a SoTL scholar for many academics, as doing so often requires constructing a new sense of scholarly identity (Galloway \& Jones, 2012; Simmons et al., 2013) and/or navigating compelling feelings of 'novice-stry' (Tremonte, 2011) as one begins working in a new field. While it is certainly not necessary for all academics to engage in SoTL (Dunwoody, Westcott, Drews, \& Hosler, 2012), such challenges that impede upon the engagement of individual scholars nonetheless bear significantly on the extent to which SoTL gains a foothold on individual campuses.

Varied strategies for negotiating these challenges and developing SoTL have been described in the literature. Many SoTL advocates have suggested that teaching and learning inquiry is more effective when aligned with institutional mission and identity (Goodburn \& Savory, 2009; Schroeder, 2007), for example, or with established disciplinary priorities (Cousin, Healey, Jenkins, Bradbeer, \& King, 2003; Dewar \& Bennett, 2010; Huber \& Morreale, 2002). Likewise, others have discussed the importance of mobilizing a network of change agents and champions who advocate for SoTL at the institution and beyond (McKinney, 2012), including senior administrators and other leaders who can affirm that SoTL is an official campus priority (Ginsberg \& Bernstein, 2011). Incentives such as awards and grants for SoTL work (Mackenzie \& Mann, 2009) and meaningful professional development opportunities (Mårtensson, Roxå, \& Olsson, 2011) have also been described as ways of encouraging and supporting individual teaching and learning scholars and contributing to the development of a critical mass. Finally, several scholars have argued that a central step in integrating SoTL within institutional cultures is recognizing such work officially within campus tenure and promotion processes (Dunwoody et al., 2012; McConnell, 2012). By including SoTL explicitly within such policies, the argument goes, universities encourage faculty members to invest precious time and energy into such work and further demonstrate that teaching and learning inquiry is a valid type of scholarly endeavour.

Another strategy gaining some momentum of late is the establishment of formal units devoted to conducting teaching and learning inquiry, commonly referred to as SoTL 'institutes.' Like research centres in other fields, SoTL institutes (in the sense of the term used in this study) are recognized organizational bodies that typically exist outside of a single academic department and focus on the creation of knowledge connected to a particular topic - in this case teaching and learning in higher education. This might include, for example, centralized research units with cross-disciplinary membership, bodies housed within a Faculty or department that work in collaboration with others across campus or beyond, or educational development centres with a prominent and active focus on conducting SoTL work. ${ }^{1}$ Several authors have positioned the establishment of such institutionally recognized bodies as a key means of enhancing and institutionalizing teaching and learning inquiry (e.g., Gale, 2009; Poole, Taylor, \& Thompson, 2007), sometimes pointing out that they can provide a useful framework for actualizing some of the strategies described above. Literature discussing organized research units in other fields also emphasizes additional benefits that attach to these units, including support for interdisciplinarity (Sá, 2007) and for collaborative scholarship (Boardman \& Corley, 
2008) — priorities that have also been established for SoTL (McKinney, 2013, Mackenzie \& Meyers, 2012). Nonetheless, with few exceptions (e.g., Hubball, Clarke, \& Poole, 2010), there exists little published information about the effective design and management of SoTL institutes specifically, nor about the experiences of scholars affiliated with these bodies. Indeed, as the examples above suggest, there is as yet no widely accepted understanding of what defines a SoTL institute, and the kinds of unit that might fall under this label are diverse. On one hand, this isn't surprising, given the comparative youth of many existing institutes and the finding that research centres in general are heterogeneous and not often thoroughly and proactively designed (Boardman \& Corley, 2008). In order to maximize the potential efficacy of such units, however, their development must be founded on a strong evidence base.

To begin to address this need, the pilot study reported here examined the perceived benefits, challenges, and key design features of organized research units devoted to teaching, learning, or education at research-intensive universities. The goal was not only to determine what such units look like, but also, more centrally, to begin to unpack how individuals affiliated with SoTL institutes experience these organizational bodies. Qualitative and quantitative data were gathered in an attempt to address three research questions:

\section{What are the characteristics of existing educational scholarship institutes at research-intensive universities?}

2. What are the perceived benefits and challenges of these institutes, according to institute members and directors?

\section{What features of institute design do members and directors believe contribute to their institutes' successes and challenges?}

\section{RESEARCH CONTEXT AND METHODOLOGY}

The research reported here was conducted at McMaster University, a medium-sized university in Ontario, Canada. In a recent visioning exercise, a campus advisory committee defined the institution as a "research-focused, student-centered" university, emphasizing that education and research should be productively intertwined and that we must take evidence-based approaches to all parts of our campus mission (Forward with Integrity Advisory Group, pp. 4-5). As part of reaching this goal, the university established in 2013 the McMaster Institute for Innovation \& Excellence in Teaching \& Learning, expanding the mandate of its existing teaching and learning centre to enhance the university's contributions to teaching and learning scholarship. The study reported here was developed to contribute to an evidence-informed plan for developing SoTL through this new institute.

Data were collected via an online survey instrument distributed to institute-affiliated personnel. In order to locate relevant potential scholarship units, I examined the categorization of the top 700 universities on the QS World University Rankings list for 2012 (http://www.topuniversities.com/) and considered all universities that were labeled "High" or "Very High" in research intensity and "Comprehensive" or "Fully Comprehensive" in subject focus. This resulted in a new list of 539 universities around the world that are roughly similar to McMaster in the areas noted. I then searched websites for these institutions for references to scholarship units focusing on higher education or on teaching and learning in higher education. This search yielded 105 relevant units at 91 universities worldwide. Subsequently, I searched the websites for these units for the email addresses 
of institute members, directors, and advisory board representatives. Following approval from the university Research Ethics Board, 2330 individuals were invited to complete an anonymous online survey consisting of both open-ended and Likert-style questions.

Survey questions asked participants to report on the features and outcomes of their teaching and learning scholarship institutes, and on their perceptions of the benefits and challenges attached to these institute characteristics. Some questions were adapted from the Carnegie Academy for the Scholarship of Teaching and Learning (CASTL) survey (http://www.carnegiefoundation.org/resources/tools-sharing). Copies of the full survey instrument are available from the author upon request. During the three weeks in which the survey was available, responses were received from 215 institute members and 30 directors/board members (a response rate of $\sim 11 \%$ overall).

Following data collection, basic descriptive statistics were computed for Likert-style survey responses, and constant comparison (Merriam, 2009) was used to analyse responses to the open-ended survey questions. In an initial open-coding phase, relevant units of meaning in the qualitative data were noted and highlighted. I then grouped and collapsed these into preliminary, higher-order categories and revisited raw responses to ensure that this initial code tree was consistent with the data. This process was repeated until a final code structure was developed. Unfortunately, due to the limited size of the research team, triangulation of interpretation was not possible. However, a rigorous analytical process was followed, and the fact that the resulting findings resonated with the quantitative data suggests that the analysis is reasonably valid-particularly for a pilot study.

Given the anonymous nature of the survey, responses were not compared based on location or institutional type, as such demographic data were not available. Instead, themes and trends were examined as they cut across the responses as a set. The extent to which perceptions of SoTL institutes might vary internationally remains a compelling question for future research.

\section{RESULTS}

\section{Perceived benefits}

Survey respondents claimed that membership in an organized scholarship unit had a number of individual and institutional benefits, echoing many of the ideas highlighted in the literature. In line with the claim that being attached to an organized scholarship unit augments scholars' collaborative networks, for instance, many respondents either agreed or strongly agreed that they had "found new colleagues and communities for work on teaching and learning" as a result of their participation in the institute on their campus. Several also suggested that membership in an organized research centre has a positive impact on scholarly output, agreeing that the quality of their teaching and learning inquiry has been enhanced, and/or that they have developed new teaching and learning research interests by virtue of being an institute member. Interestingly, a much lower percentage of participants agreed or strongly agreed with the assertion that the amount of teaching and learning scholarship they produce has increased as a result of their institute membership, suggesting that the impact of such units on research productivity may be related more to perceived quality than to quantity. A complete breakdown of impact statements provided in this question and participant responses can be found in Table 1. 
Table 1. Perceived Impacts of Institute Affiliation

\begin{tabular}{|c|c|c|c|c|c|c|}
\hline \multirow[b]{3}{*}{ AREA OF IMPACT } & \multirow[b]{2}{*}{ NUMBER OF } & \multicolumn{5}{|c|}{ NUMBER OF RESPONSES BY RANKING } \\
\hline & & STRONGLY & & & STRONGLY & UNSURE/ \\
\hline & RESPONSES & DISAGREE & DISAGREE & AGREE & AGREE & NA \\
\hline $\begin{array}{l}\text { Found new colleagues } \\
\text { and communities }\end{array}$ & 181 & 4 & 18 & 67 & 84 & 8 \\
\hline $\begin{array}{l}\text { Developed new SoTL } \\
\text { interests }\end{array}$ & 180 & 5 & 26 & 82 & 58 & 9 \\
\hline $\begin{array}{l}\text { Heightened interest in } \\
\text { reading SoTL }\end{array}$ & 182 & 5 & 31 & 68 & 68 & 10 \\
\hline Enhanced SoTL quality & 173 & 6 & 19 & 75 & 54 & 19 \\
\hline $\begin{array}{l}\text { Contributed to meeting } \\
\text { institutional priorities }\end{array}$ & 182 & 9 & 23 & 82 & 49 & 19 \\
\hline Changed course design & 178 & 10 & 33 & 67 & 49 & 19 \\
\hline $\begin{array}{l}\text { Changed teaching } \\
\text { expectations }\end{array}$ & 177 & 9 & 35 & 65 & 50 & 18 \\
\hline $\begin{array}{l}\text { Engaged in inter-depart- } \\
\text { mental, collaborative SoTL }\end{array}$ & 177 & 7 & 40 & 58 & 54 & 18 \\
\hline $\begin{array}{l}\text { Trained new SoTL } \\
\text { scholars (inc. students) }\end{array}$ & 170 & 14 & 26 & 62 & 45 & 23 \\
\hline $\begin{array}{l}\text { Changed expectations } \\
\text { for students' learning }\end{array}$ & 177 & 12 & 36 & 62 & 47 & 20 \\
\hline $\begin{array}{l}\text { Influenced teaching at } \\
\text { the university beyond the } \\
\text { department }\end{array}$ & 172 & 12 & 35 & 66 & 37 & 22 \\
\hline $\begin{array}{l}\text { Changed assessments } \\
\text { used in course }\end{array}$ & 170 & 9 & 40 & 54 & 47 & 20 \\
\hline $\begin{array}{l}\text { Influenced teaching in the } \\
\text { department }\end{array}$ & 174 & 11 & 36 & 59 & 41 & 27 \\
\hline Increased SoTL quantity & 172 & 9 & 45 & 54 & 37 & 27 \\
\hline $\begin{array}{l}\text { Documented improve- } \\
\text { ments in students' learning }\end{array}$ & 169 & 9 & 45 & 52 & 34 & 29 \\
\hline $\begin{array}{l}\text { Enhanced prospects for } \\
\text { career advancement }\end{array}$ & 178 & 37 & 38 & 49 & 28 & 26 \\
\hline
\end{tabular}

In responses to an open-ended question, participants reiterated some of these points and described other benefits as well. Most notably, a large number of respondents (37\%) mentioned the way in which belonging to a group of this sort affords individuals valuable opportunities for community, collaboration, and networking —often across disciplinary lines. One member noted valuing the "collegial environment" and "intellectual engagement from a range of scholars" afforded by his/her institute, for instance, while another suggested that the primary benefit of his/her unit was the way in which it constitutes "a place to exchange ideas and be exposed to new perspectives." In some cases, respondents indicated that these opportunities for community were especially valued in light of the lack of attention to teaching, learning, and SoTL in their home departments, and 
the sense of loneliness or seclusion such disinterest can cause. As one participant put it, "[the centre] gives a community, support and focus to my research that I do not get in my home department” (Member).

Other responses (31\%) suggested that institute membership is also seen as beneficial for scholars insofar as it provides them access to a wide range of resources and supports that might not be available otherwise. These individuals valued opportunities to receive funding, administrative support, research assistants, and space for research through their units, for instance, as well as access to training opportunities and to consultants, experts, and mentors in the field. "Our Institute brings in amazing visiting researchers, as collaborators and as presenters," one member wrote, while another listed learning from colleagues, access to literature, and the opportunity to apply for institute-specific grants as the primary benefits of belonging to a scholarship unit. Such responses suggest that these kinds of intellectual, practical, and material supports are central aspects of SoTL units' ability to support enhanced educational scholarship.

Six percent of participants responding to this open-ended question also suggested that their units served to increase the recognition and reputation of educational scholarship on their campuses, providing what one respondent referred to as institutional "legitimacy for research on teaching and learning” (Member). Nonetheless, there were also indications that there is still work to be done in this regard. One individual claimed, for instance, that his/her unit is "Starting to increase the acceptability of TL research at [the university], but only somewhat. TL research is still the poor cousin of discipline-based research outside of the School of Education" (Member).

Finally, some respondents also suggested that their institutes have had a demonstrable impact on the quality of teaching and learning practices. For example, $16 \%$ claimed that the research generated by their institutes had resulted in enhanced teaching practices or policies on their campuses, while $6 \%$ claimed that their units contributed to improved student learning, retention, and/or success. While these claims demand substantiation via research examining actual teaching activities and student learning outcomes, they nonetheless make clear that some institute participants believe their institute-sponsored work to be exerting a significant impact on educational quality at their institutions.

\section{Perceived challenges and shortcomings}

In spite of these benefits, respondents also described several challenges faced by their institutes. Alongside the widespread perception that the units investigated in this study helped to facilitate the building of vibrant scholarly communities, for example, the data also reflected a less common sense that these bodies did not always live up to their full potential in this regard. In response to an open-ended question about the main shortcomings of their institutes, for example, $7 \%$ of respondents specified that their centre generated limited communication or collaboration between scholars, a point that was also raised by $4 \%$ of respondents to an open-ended question about the main challenges people experience as institute participants. One member cited a "Lack of deep and substance based collaboration" as a shortcoming, for instance, while another wrote that his/her centre "doesn't try to bring together folks for research proposals that could explore broader topics and capitalize on collaborations." At times, this limited collaboration was connected specifically to infrequent meetings and sporadic communication between members. As one respondent put it, "The institute is informal and the development group meets only 
a few times each semester. It is difficult to carry on sustained conversations or develop collaborative projects" (Member).

Just as some participants faulted their units for not generating sufficient collaboration between members, others $(n=4)$ believed that their institutes were not sufficiently engaged in interdisciplinary inquiry. One member described his/her institute as "interdisciplinary in name, but not really in practice," while a director wrote that a central challenge is to "keep members motivated to become/stay involved in interdisciplinary research." In other cases, respondents $(n=8)$ acknowledged that their units are in fact active, multidisciplinary hubs, but suggested that this diversity of outlooks and approaches can itself be challenging to navigate. "With many diverse disciplines involved and many different focuses," one member wrote, "it is sometimes difficult to get everyone moving in the same direction." While the potential for interdisciplinary collaboration was widely positioned as a central benefit of the units examined in this study, the small number of participants describing challenges related to interdisciplinarity suggests that such crossdisciplinary work is neither a given nor an entirely unproblematic aspect of institute functioning.

Limited resources were another oft-cited obstacle-one which was raised in 34\% of responses to the question about shortcomings and in $12 \%$ of responses to the question about challenges experienced by institute members. In a typical response, one director wrote that the central issue plaguing his/her centre is a "Lack of people-power and other resources," while another noted, "We have very little in the way of dedicated resources: time, money, and personnel." In addition to a sense of general under-resourcing, the data also revealed indications that some participants believe the resources that their units are able to provide are not always sufficient. Amongst other complaints, for example, respondents reported shortcomings in institute support staff and SoTL training programs. These comments reiterate that many individuals perceive access to resources to be a primary benefit of institute membership, while simultaneously underlining that such benefits may be increasingly difficult for organized scholarship units to provide effectively in challenging financial times.

Like insufficient resources, a general lack of time for members to participate in unit activities was another challenge frequently attached to the educational scholarship bodies examined in this study. Echoing arguments about the increasingly complex nature of the demands on faculty time, $9 \%$ and $23 \%$ of responses to the two open-ended questions described above focused on what one member called a "Lack of time to conduct research projects due to other responsibilities." Some reported that this challenge is exacerbated by the fact that institute participation is not fully recognized as part of their job duties, leaving them torn between unit activities and the requirements of their home departments. As one individual noted,

My current official job role also is ... at odds with participation in the institute, which has set frustrating limits on the ways in which I can contribute. It can feel like participation has to be on top of my official work. (Member)

As this comment suggests, the perception that institute activities exist in tension with responsibilities to home departments can seriously threaten active participation in organized scholarship units, particularly in view of how busy academic lives have become. 
The possibility of SoTL work being sacrificed to other responsibilities is especially compelling given that many respondents, again echoing the literature, also reported that the type of scholarship in which their units engage is generally undervalued. Indeed, the relatively low esteem in which SoTL is held within research-intensive universities was positioned by survey respondents as an especially prominent issue, being raised in $30 \%$ of all responses to the shortcomings question and $22 \%$ of responses to the membership challenges question. Several participants claimed that colleagues in their home departments are uninterested in or do not respect SoTL work, for instance, while others argued that this undervaluing extends beyond their individual departments to the university as a whole.

Finally, running alongside the more prevalent perception that the institutes examined in this study have a positive impact on teaching and learning, 13 respondents reported an opposing belief that their centres are either insufficiently influential or have not been satisfactorily assessed. One director suggested that his/her institute "directly impacts only the 15 or so fellows within [it]," for instance, while a member wrote that the unit with which s/he is affiliated "gives people something to think about, but doesn't really change practice." Such concerns, while comparatively infrequent in the data, nevertheless underline the importance of planning carefully the ways in which scholarship conducted in an institute can be effectively translated into pedagogical practice.

\section{Institute design}

On another multiple-select question, participants indicated which of several resources and supports are offered by their institutes and ranked the importance of these features to achieving the unit's goals (see Table 2). In spite of potential variability in other respects, most institutes represented in this data set appeared to offer a number of similar services and supports. Responses suggested that $90 \%$ of the features listed were available through at least $50 \%$ of respondents' institutes. The most frequently provided features were regular meetings with other institute members (85\%), workshops or courses on topics in teaching and learning research (83\%), and consultation with knowledgeable research personnel ( $81 \%)$.

Beyond indicating the most common attributes of the SoTL units included in this study, Table 2 also clarifies which of these features members perceive as particularly important to their units' success. Literature resources, grants, physical space for research, consultation with knowledgeable personnel, regular meetings with other institute members, the creation of targeted research groups, and workshops/courses on teaching and learning research topics stand out as especially significant. Each of these features was rated "very important" by at least half of the relevant participants.

A subsequent question, which asked participants to indicate which of the factors listed in Table 2 is most important to their institute's ability to foster educational scholarship, yielded similar results. Grants were the most frequently selected response (29\%), and regular meetings, targeted research groups, consultation with experts, and workshops or courses were selected by $11 \%$ to $7 \%$ of respondents each. Perhaps not surprisingly, these attributes overlap strongly with some of the primary benefits participants connected to institute membership in other survey questions, insofar as they include activities that encourage the creation of community and collaborative scholarship (regular meetings, targeted research groups), and examples of resources available to members (grants, training and mentorship opportunities). As such, these responses reaffirm some of the advantages 
Table 2. Institute Features and Their Perceived Importance

\begin{tabular}{|c|c|c|c|c|c|}
\hline & & NUM & ER OF RESPON & SES BY RAN & KING \\
\hline & & NOT OFFERED & & OFFERED \& & OFFERED \\
\hline & NUMBER OF & BY MY & OFFERED \& & SOMEWHAT & \& VERY \\
\hline INSTITUTE FEATURE & RESPONSES & INSTITUTE & UNIMPORTANT & IMPORTANT & IMPORTANT \\
\hline$\underline{\text { Library/literature resources }}$ & 164 & 48 & 12 & 32 & 72 \\
\hline $\begin{array}{l}\text { Grants/seed money for } \\
\text { research }\end{array}$ & 163 & 51 & 3 & 45 & 64 \\
\hline Physical space for research & 168 & 81 & 10 & 28 & 49 \\
\hline $\begin{array}{l}\text { Consultation with knowl- } \\
\text { edgeable research personnel }\end{array}$ & 158 & 30 & 7 & 53 & 68 \\
\hline $\begin{array}{l}\text { Regular meetings with other } \\
\text { institute members }\end{array}$ & 157 & 23 & 11 & 54 & 69 \\
\hline $\begin{array}{l}\text { Creation of targeted } \\
\text { research groups }\end{array}$ & 148 & 50 & 10 & 39 & 49 \\
\hline $\begin{array}{l}\text { Workshops/courses on } \\
\text { teaching \& learning research }\end{array}$ & 163 & 27 & 12 & 56 & 68 \\
\hline Grant writing support & 158 & 70 & 10 & 35 & 43 \\
\hline Research Assistants & 152 & 95 & 7 & 23 & 27 \\
\hline $\begin{array}{l}\text { Fellowships for grad } \\
\text { students/post-doctoral } \\
\text { researchers }\end{array}$ & 150 & 69 & 9 & 34 & 38 \\
\hline Administrative support & 162 & 63 & 9 & 45 & 45 \\
\hline Research tools \& technology & 164 & 47 & 8 & 56 & 53 \\
\hline $\begin{array}{l}\text { Support for integrating } \\
\text { research into teaching } \\
\text { practice }\end{array}$ & 155 & 58 & 16 & 38 & 43 \\
\hline Technology support & 167 & 57 & 14 & 48 & 48 \\
\hline $\begin{array}{l}\text { Institute-sponsored visiting } \\
\text { scholars }\end{array}$ & 151 & 49 & 15 & 43 & 44 \\
\hline $\begin{array}{l}\text { Opportunities to lead } \\
\text { courses/workshops on } \\
\text { SoTL issues }\end{array}$ & 153 & 41 & 15 & 53 & 44 \\
\hline Access to institutional data & 142 & 68 & 15 & 30 & 29 \\
\hline $\begin{array}{l}\text { On campus conferences/ } \\
\text { symposia }\end{array}$ & 156 & 31 & 9 & 68 & 48 \\
\hline $\begin{array}{l}\text { Electronic communication } \\
\text { platform for resource sharing }\end{array}$ & 160 & 46 & 20 & 54 & 40 \\
\hline Institute-sponsored retreats & 152 & 92 & 14 & 26 & 20 \\
\hline $\begin{array}{l}\text { Publicity for research } \\
\text { activities (e.g., campus } \\
\text { newsletter) }\end{array}$ & 158 & 32 & 26 & 61 & 39 \\
\hline
\end{tabular}


participating members attribute to their SoTL units, and further specify design features considered to be important means of securing them.

\section{DISCUSSION}

The study reported here contributes to an enhanced understanding of the ways in which educational scholarship institutes are organized and structured at research-intensive universities worldwide. It also identifies a number of central benefits and challenges attached to such entities, as perceived by a portion of the scholars who populate them. Many of the findings, including the potential for institutes to encourage collaboration, community, and interdisciplinarity, the ways in which they can provide academics with valued resources and capacity-building opportunities, and the extent to which they are challenged by scholar workload and by the undervaluing of SoTL in institutions and departments, corroborate and extend arguments made in the scholarship of teaching and learning and organized research unit literatures. At the same time, this research also suggests new considerations, such as a sense that some of the most common institute features (e.g., publicity for research, conferences), while still seen as relatively important, may not be the elements valued most by institute participants. Perhaps foremost amongst the provocative ideas prompted by the data is the notion that, for many individuals, educational scholarship units can be marred by insufficient collaboration and communication. While not surprising on one hand, this rarely discussed issue emphasizes that the community, collegiality, and interdisciplinarity that are seen as hallmarks of such units are neither simple to achieve nor assured. Rather, these must be actively planned for and fostered, just as they must in other contexts.

As a whole, these preliminary findings highlight a number of considerations that might be brought to bear on the design of organized SoTL institutes. While the pilot nature of the study suggests that care should be taken when building recommendations from the data, the fact that many of the suggestions arising from the present research are well supported in the SoTL literature provides further support for their legitimacy. Indeed, one of the most striking outcomes of this study is the fact that it largely corroborates much of what is already known about developing SoTL, thereby suggesting that many of these established principles continue to apply within the particular context of organized research institutes. While such institutes might have a number of benefits, then, they are clearly not 'magic bullets' in terms of supporting and institutionalizing teaching and learning inquiry, and existing knowledge about these issues should be meaningfully deployed in order to help institutes meet their full potential. This study aids in this process by pointing toward specific elements of the extant literature that might be most important to consider when engaging in institute design. Several of these are summarized below.

\section{Developing priority areas for institute scholarship}

In the present survey, respondents positioned the creation of research groups around targeted areas of interest as one of the design features most significant to their institutes' successes. This finding resonates productively with literature that suggests the value of aligning SoTL with established priorities of the institution, on one hand (Schroeder, 2007), and of individual departments and disciplines on the other (Dewar \& Bennett, 2010). Targeted research groups might be established around priority questions at each of these levels. 
On a similar note, Poole et al. (2007) argue that much of the promise of institutes lies in their capacity to provide centralized infrastructure for inquiry addressing institutional concerns. This study offers preliminary support for this assertion, as $72 \%$ of individuals (Table 1) claimed that they have contributed to meeting their universities' central priorities as a result of participating in their institutes. Finding ways to additionally marry unit scholarship to disciplinary priorities, perhaps drawing from approaches such as those described by Cousin et al. (2003), would likely also prove beneficial, particularly insofar as this could contribute to shifting departmental cultures that are currently unreceptive to such work.

Of course, department-driven research should not be pursued to the detriment of work that transcends disciplinary boundaries. In fact, several writers have suggested that discipline-focused approaches to SoTL can and should co-exist alongside opportunities for interdisciplinary work and exchange (e.g., Fanghanel, 2013; McKinney, 2013). Likewise, respondents to the present survey, echoing the literature about organized research institutes in other fields (Sá, 2007), emphasized the benefits of communicating with individuals across departmental boundaries and engaging in interdisciplinary research via their institutes. To this end, the priority areas established for institute scholarship might intentionally and strategically include interdisciplinary inquiry in addition to addressing disciplinary priorities. Such a dual focus would also respond to the concern, likewise raised in this survey, that scholarship in some institutes is not sufficiently interdisciplinary or collaborative.

\section{Building a diverse institute community}

Perhaps the most pronounced theme emerging from the present research was the potential for an institute to contribute to developing a vibrant and collaborative community around SoTL work. Corroborating claims about centralized SoTL initiatives in the literature (Hubball et al., 2010), nearly $40 \%$ of participants describing the benefits of their institutes in this study mentioned the way in which membership permitted them to work with a broad network of colleagues they might not otherwise meet. Likewise, when such community was perceived to be lacking, survey respondents noted this as a primary shortcoming. As such, this research underlines that a large, diverse, and collegial institute community may be both vital for success and challenging to foster.

As part of this process, a primary task for any SoTL institute will be to engage a wide range of participants and encourage meaningful collaboration amongst them. In order to emphasize that SoTL is potentially valid work for all academics (Shulman, 2011), and thus to combat the sense that it is not "real" scholarship (Chalmers, 2011), faculty participants should ideally be drawn from across disciplines, represent a variety of career stages, and include those known as high-level scholars in their fields (Becker, 2008). Based on the present data, it might also prove productive to develop joint faculty appointments with responsibilities to the institute and to a department on campus. In light of the complex demands on faculty time, such appointments would create occasions wherein institute work is an official part of scholars' job responsibilities with time allotted to it, thereby minimizing the under-prioritizing reported in this study and elsewhere. Again pulling from recommendations in the broader SoTL literature, educational developers should likewise be included wherever practicable (Patel, 2014), as should undergraduate and graduate students (Felten, 2013; Healey, Flint, \& Harrington, 2014). Extending this net- 
work of participants beyond the institutional context might also prove valuable, providing an augmented sense of community for institute scholars (Simmons et al., 2013), and simultaneously enhancing the regard in which the institute and its work are held by virtue of external validation (Ginsberg \& Bernstein, 2011).

Of course, more than simply deploying these proposed strategies to assemble a diverse array of people, care must be taken to foster meaningful connections amongst members of this group. Reflecting the survey finding that regular meetings of institute members is both a common feature of the units studied and one perceived as especially important to their success, a number of opportunities should be planned for scholars affiliated with an institute to work together actively and collaboratively. Well documented approaches like learning communities (Richlin \& Cox, 2004) could be deployed to this end, for instance, as might strategic uses of grants to foster collaborative, interdisciplinary research (McKinney \& Jarvis, 2009).

As part of this plan for ensuring meaningful and effective connections amongst institute scholars, attention should also be paid to the challenges that can attach to working across disciplinary lines. As Huber (2013) — like several participants in this studyexplains, "leaving one's disciplinary home is worthwhile, but it can also be really hard" (p. xiii). In order to help institute members through this process, multi-disciplinary teams might be encouraged to discuss and come to common understandings of relevant terms (Poole, 2013), and should include mentors who are experienced in interdisciplinary work wherever possible (Meta Robinson et al., 2013). Given that interdisciplinarity and diversity have been positioned as key elements of educational scholarship institutes and of SoTL more broadly, building such recommendations into support for institute members may well be key to such bodies' success.

\section{Providing meaningful resources, incentives, and PD opportunities}

Like the development of community, access to resources has been named frequently as an essential feature of organized scholarship units. In the present study, over $30 \%$ of respondents describing the benefits of their institutes mentioned funds, professional development opportunities, and/or other resources as especially valued and valuable, confirming claims reported in the literature pertaining to research centres in other fields (Boardman \& Bozeman, 2007; Sá \& Oleksiyenko, 2011). With this in mind, it seems crucial for SoTL institutes to provide access to meaningful resources and incentives if they are to attract and retain the diverse body of scholars called for above.

Moderate grants might be provided for members, for instance, especially considering that such funds are now a fairly common offering (Mackenzie \& Mann, 2009) and that they were the feature most frequently selected as most important to an institute's success in this survey. At the same time, SoTL institutes might also offer members access to professional development opportunities that will help them advance as SoTL scholars. Not surprisingly, given the oft-described challenges of developing a SoTL identity and the potentially unsettling feelings that can attach to this process (Tremonte, 2011), consultations with knowledgeable research personnel and workshops or courses on teaching and learning research topics were both labeled "very important" by at least $50 \%$ of survey participants who noted that their institutes provided such supports. At the same time, some published work (Donnermeyer, Kalish, \& Johnson, 2009) suggests that workshops do 
not always attract participants, nor engage individuals who do take part as extensively and meaningfully as would be ideal. To that end, alternative models of professional development might also be explored, such as the faculty learning communities (Richlin \& Cox, 2004) referred to above and other collaborative and cohort-based programs described in the literature (e.g., Hubball et al., 2010; Marquis, Healey, \& Vine, 2014). Significantly, these alternate models would also provide additional opportunities for community building and mentorship, and thus further assist in creating the collaborative environment required for a successful and productive institute.

\section{Developing a sustainable funding plan}

It goes without saying that considerable financial resources would be required to implement many of the recommendations advanced thus far. While it certainly might not be possible to provide for all of these suggestions in all cases, it is not unreasonable to propose that a number of them must be realized if SoTL institutes are going to deliver on their promise. Indeed, the most common shortcoming that participants in this study attributed to the units with which they are affiliated was a lack of money and other resources, which many saw as impinging considerably on what their institutes were able to accomplish. To that end, it may well be imperative that sufficient, long-term funding is acquired to support SoTL institutes and their work.

It should be underlined that requiring such institutes to support themselves via the acquisition of grant funds is not a sustainable plan, particularly since, as one survey participant put it, "education research does not bring big research funding" (Member). Moreover, existing literature about research institutes suggests this type of structure can also have negative impacts on institute scholarship, requiring members to devote substantial amounts of time to fundraising or to conducting projects that might suit grantors but deviate from their own or the institute's focus areas (Sá \& Oleksiyenko, 2011). While members and staff might certainly pursue grant opportunities actively, institute budgets must not finally be dependent on such funds.

\section{CONCLUSION: FINDINGS FROM-AND QUESTIONS FOR-RESEARCH}

Like all research, the present study is not without its limitations. Given that it was focused largely on participants' self-reported experiences within teaching and learning scholarship institutes, it did not directly assess the benefits, challenges, and impacts of such bodies. Moreover, a volunteer bias may be present, since participants self-selected to take part in the research. The relatively low response rate also means that data were not collected from people affiliated with many of the institutes, limiting generalizability, and that meaningful correlations between design features and perceived benefits/challenges could not be calculated. It should also be recalled that a broad definition of 'educational scholarship institute' was used in selecting units for the study. This might also be construed as a limitation, insofar as it brings together a diverse range of units under one label. Future research might consider adopting a more precise classification system that would allow for greater generalization.

Nevertheless, taken as a pilot, the present study provides several preliminary insights directly relevant to the research goals and provokes a number of significant considerations that might be explored fruitfully in the future (perhaps using other approaches, such 
as Delphi techniques or in-depth case studies). It makes clear its participants' reported perceptions of the institutes in which they work and underlines shared views (amongst many taking part) of benefits, challenges, and impacts regardless of potential differences in unit type. Ironically, perhaps its most compelling finding is that it finds little new. Insofar as the issues described here in relation to SoTL institutes resonate closely with literature discussing SoTL broadly, the survey points to the relevance of bringing this larger scholarly context to bear on questions of institute design - a task I attempted to initiate in the recommendations provided above. While this process seems likely to have tangible benefits for those developing or working within SoTL research centres, the sheer familiarity of the findings also perhaps underscores the need for us, as scholars interested in developing and institutionalizing SoTL, to ask different kinds of research questions, in different ways, moving forward.

Potential international differences in fostering and supporting SoTL, for example, which the present survey could not unpack due to its anonymous nature and limited demographic questions, represent one such issue that demands further exploration. As Hoon and Looker (2013) point out, SoTL has developed largely as a Western, Englishspeaking field, and thus has frequently excluded a number of voices from around the world. In the present study, familiar themes were found across a body of data drawn from international participants, but it remains to be seen whether the predominance of these ideas was based on their 'universal' nature or simply on the fact that more people from Western countries participated. Research that more fully unpacks the extent to which issues well known in the SoTL literature translate to non-Western contexts would be beneficial to our understanding of the development of teaching and learning inquiry in institutes and beyond, even as it works to open the field to a wider range of voices.

As noted by a reviewer of an earlier version of this manuscript, the familiarity of the findings reported here might also be taken as an indication of the need to consider not only how SoTL work is facilitated, but why scholars might wish to engage this type of work in the first place. In order to supplement explorations of experiences and impact, we might begin to turn to questions of scholar motivation and expectations, comparing these in turn to reported perceptions of benefit and challenge. Theoretical conceptions like Åkerlind's (2008) model of 'being a researcher'-a framework that describes qualitatively different conceptions amongst scholars of the nature and purpose of researchcould inform such work productively. The notion of substantive differences in what individuals make of scholarship (in this case SoTL) stands to generate interesting questions about how we might best support scholars with differing understandings, and perhaps about the practicalities and ethics of establishing institutes and other SoTL initiatives that favour particular conceptions over others. Indeed, further theoretical grounding of studies connected to SoTL development would be beneficial more generally, particularly if scholars were to begin to draw from a broad range of approaches that might complement and extend useful socio-cultural models now relatively common to research in this area (e.g., Mårtensson et al., 2011; Williams et al., 2013). While the findings reported here are useful in corroborating the literature and indicating that it might be soundly applied to a specific and growing context, then, they are perhaps especially provocative for how their very sameness might push scholars of SoTL development to broaden the boundaries of our work. 


\section{ACKNOWLEDGEMENTS}

I would like to thank the study participants for sharing their time and ideas. I'm also grateful to Dr. Arshad Ahmad for his insights on a previous draft, and to Dr. Sue Vajoczki who contributed significantly to this work until her death in 2012.

Elizabeth Marquis is Assistant Professor in the Arts \& Science program and the McMaster Institute for Innovation and Excellence in Teaching and Learning at McMaster University.

\section{NOTES}

1. Throughout this article, I also refer to such entities as SoTL/educational/teaching and learning scholarship units or research centres in order to avoid repetitive word choice.

\section{REFERENCES}

Åkerlind, G.S. (2008). An academic perspective on research and being a researcher: An integration of the literature. Studies in Higher Education, 33(1), 17-31.

Becker, W.E. (2008). An unrealized vision for SoTL. International Commons, 3(1), 10-11.

Boardman, C., \& Bozeman, B. (2007). Role strain in university research centers. The Journal of Higher Education, 78(4), 430-463.

Boardman, C., \& Corley, E.A. (2008). University research centers and the composition of research collaborations. Research Policy, 37(5), 900-913.

Boshier, R. (2009). Why is the scholarship of teaching and learning such a hard sell? Higher Education Research \& Development, 28(1), 1-15.

Brew, A. (2010). Transforming academic practice through scholarship. International Journal for Academic Development, 15(2), 105-116.

Chalmers, D. (2011). Progress and challenges to the recognition and reward of the scholarship of teaching in higher education. Higher Education Research \& Development, 30(1), $25-38$.

Cousin, G., Healey, M., Jenkins, A., Bradbeer, J., \& King, H. (2003). Raising educational research capacity: A discipline-based approach. In C. Rust (Ed.), Improving student learning: Theory and practice - 10 years on. Oxford, England: Oxford Centre for Staff and Learning Development, Oxford Brookes University. Retrieved from www2.glos.ac.uk/gdn/confpubl /cousinetal.doc

Dewar, J. M., \& Bennett, C. (2010). Situating SoTL within the disciplines: Mathematics in the United States as a case study. International Journal for the Scholarship of Teaching and Learning, 4(1). Retrieved from http://digitalcommons.georgiasouthern.edu/ij-SoTL/vol4 /iss $1 / 14 /$

Donnermeyer, J.F., Kalish, A., \& Johnson, T. (2009). Many are called, but few show up: Building scholarly communities of teachers. Transformative Dialogues, 3(1). Retrieved from http:// www.kpu.ca/td/past-issues/3-1

Dunwoody, P.T., Westcott, K., Drews, D., \& Hosler, J. (2012). Case study of a shoe-string SoTL center. International Journal for the Scholarship of Teaching and Learning, 6(1). Retrieved from http://digitalcommons.georgiasouthern.edu/ij-SoTL/vol6/iss1/21/ 
Fanghanel, J. (2013). Going public with pedagogical inquiries: SoTL as a methodology for faculty professional development. Teaching and Learning Inquiry, 1(1), 59-70.

Felten, P. (2013). Principles of good practice in SoTL. Teaching and Learning Inquiry, 1(1), $121-125$.

Forward with Integrity Advisory Group (2012). Forward with integrity: The emerging landscape. Retrieved from http://www.mcmaster.ca/presidentsoffice/priorities/ag_report.html

Gale, R. (2009). Scholarship in support of institutional change ... Institutional change in support of scholarship. MountainRise, 5(3). Retrieved from http://mountainrise.wcu.edu /index.php/MtnRise/article/view/128/95

Galloway, K., \& Jones, P. (2012). Scholarship in the discipline and higher education: The need for a fusion epistemology focused on academic identity. Higher Education Research \& Development, 31(6), 931-933.

Ginsberg, S.M., \& Bernstein, J.L. (2011). Growing the scholarship of teaching and learning through institutional culture change. Journal of the Scholarship of Teaching and Learning, 11(1), 1-12. Retrieved from http://joSoTL.indiana.edu/issue/view/166

Goodburn, A., \& Savory, P. (2009). Integrating SoTL into instructional and institutional processes. MountainRise, 5(3). Retrieved from http://mountainrise.wcu.edu/index.php /MtnRise/ article/view/131/98

Healey, M., Flint, A., \& Harrington, K. (2014). Engagement through partnership: Students as partners in learning and teaching in higher education. York, England: HE Academy. Retrieved from: https://www.heacademy.ac.uk/engagement-through-partnership-students -partners-learning-and-teaching-higher-education.

Hoon, C.H., \& Looker, P. (2013). On the margins of SoTL discourse: An Asian perspective. Teaching and Learning Inquiry, 1(1), 131-145.

Hubball, H., Clarke, A., \& Poole, G. (2010). Ten-year reflections on mentoring SoTL research in a research-intensive university. International Journal for Academic Development, 15(2), 117-129.

Huber, M.T. (2013). Foreword. In K. McKinney (Ed.), The scholarship of teaching and learning in and across the disciplines (pp. ix-xiv). Bloomington, IN: Indiana University Press.

Huber, M.T., \& Morreale, S.P. (2002). Disciplinary styles in the scholarship of teaching and learning: Exploring common ground. Sterling, VA: Stylus.

Hutchings, P., Huber, M. T., \& Ciccone, A. (2011). Getting there: An integrative vision of the scholarship of teaching and learning. International Journal for the Scholarship of Teaching and Learning, 5(1). Retrieved from http://digitalcommons.georgiasouthern.edu/ij-SoT L/vol5/iss $1 / 31 /$

Mackenzie, J., \& Mann, S. (2009). Changing academic practice at a UK research-intensive university through supporting the scholarship of teaching and learning (SoTL). Transformative Dialogues, 3(1). Retrieved from http://www.kpu.ca/td/past-issues/3-1

MacKenzie, J., \& Meyers, R.A. (2012). International collaboration in SoTL: Current status and future direction. International Journal for the Scholarship of Teaching and Learning, 6(1). Retrieved from http://digitalcommons.georgiasouthern.edu/ij-SoTL/vol6/iss1/4/ 
Marquis, E., Healey, M., \& Vine, M. (2014). Building capacity for the scholarship of teaching and learning (SoTL) using international collaborative writing groups. The International Journal of the Scholarship of Teaching \& Learning, 8(1). Retrieved from: http://digitalcommons .georgiasouthern.edu/ij-SoTL/vol8/iss1/12/

Mårtensson, K., Roxå, T., \& Olsson, T. (2011). Developing a quality culture through the scholarship of teaching and learning. Higher Education Research \& Development, 30(1), 51-62.

McConnell, C. (2012). Developing a SoTL campus initiative: Reflections on creating sustainable impact. Transformative Dialogues, 6(2). Retrieved from http://www.kpu.ca/td/past -issues/6-2

McKinney, K. (2012). Making a difference: Application of SoTL to enhance learning. Journal of the Scholarship of Teaching and Learning, 12(1), 1-7. Retrieved from http://joSoTL indiana.edu/issue/view/177

McKinney, K. (Ed.). (2013). The scholarship of teaching and learning in and across the disciplines. Bloomington, IN: Indiana University Press.

McKinney, K., \& Jarvis, P. (2009). Beyond lines on the CV: Faculty applications of their scholarship of teaching and learning research. International Journal for the Scholarship of Teaching and Learning, 3(1). Retrieved from http://digitalcommons.georgiasouthern.edu/ij-SoTL /vol3/iss1/7/

Merriam, S.B. (2009). Qualitative research: A guide to design and implementation (3rd ed.). San Francisco, CA: Jossey-Bass.

Meta Robinson, J., Gresalfi, M., Sievert, A.K., Dowell Kearns, K., Booth Christensen, T., \& Zolan, M.E. (2013). Talking across the disciplines: Building communicative competence in a multidisciplinary graduate-student seminar on inquiry in teaching and learning. In K. McKinney (Ed.), The scholarship of teaching and learning in and across the disciplines (pp. 186-199). Bloomington, IN: Indiana University Press.

Mighty, J. (2013). One important lesson I've learned from my involvement with SoTL. Teaching and Learning Inquiry, 1(1), 113-116.

Patel, F. (2014). Promoting a culture of scholarship among educational developers: Exploring institutional opportunities. International Journal for Academic Development, 19(3), 242-254.

Poole, G. (2013). Square one: What is research? In K. McKinney (Ed.), The scholarship of teaching and learning in and across the disciplines (pp. 135-151). Bloomington, IN: Indiana University Press.

Poole, G., Taylor, L., \& Thompson, J. (2007). Using the scholarship of teaching and learning at disciplinary, national and institutional levels to strategically improve the quality of postsecondary education. International Journal for the Scholarship of Teaching and Learning, 1(2). Retrieved from http://digitalcommons.georgiasouthern.edu/ij-SoTL/vol1/iss2/3/

Richlin, L., \& Cox, M. D. (2004). Developing scholarly teaching and the scholarship of teaching and learning through faculty learning communities. New Directions for Teaching and Learning, 2004(97), 127-135.

Sá, C. M. (2007). "Interdisciplinary strategies" in U.S. research universities. Higher Education, 55(5), 537-552. 
Sá, C. M., \& Oleksiyenko, A. (2011). Between the local and the global: Organized research units and international collaborations in the health sciences. Higher Education, 62(3), 367-382.

Schroeder, C. M. (2007). Countering SoTL marginalization: A model for integrating SoTL with institutional initiatives. International Journal for the Scholarship of Teaching and Learning, 1(1). Retrieved from http://digitalcommons.georgiasouthern.edu/ij-SoTL/vol1/iss1/15/

Shulman, L. S. (2011). The scholarship of teaching and learning: A personal account and reflection. International Journal for the Scholarship of Teaching and Learning, 5(1). Retrieved from http://digitalcommons.georgiasouthern.edu/ij-SoTL/vol5/iss1/30/

Simmons, N., Abrahamson, E., Deshler, J.M., Kensington-Miller, B., Manarin, K., Morón-García, S., Oliver, C., \& Renc-Roe, J. (2013). Conflicts and configurations in a liminal space: SoTL scholars' identity development. Teaching and Learning Inquiry, 1(2): 9-21.

Tremonte, C. M. (2011). Window shopping: Fashioning a scholarship of interdisciplinary teaching and learning. International Journal for the Scholarship of Teaching and Learning, 5(1). Retrieved from http://digitalcommons.georgiasouthern.edu/ij-SoTL/vol5/iss1/26/

Walker, J.D., Baepler, P., \& Cohen, B. (2008). The scholarship of teaching and learning paradox. Results without rewards. College Teaching, 56(3), 183-189.

Williams, A.L., Verwoord, R., Beery, T.A., Dalton, H., McKinnon, J., Strickland, K., Pace, J., \& Poole, G. (2013). The power of social networks: A model for weaving the scholarship of teaching and learning into institutional culture. Teaching and Learning Inquiry, 1(2), 49-62. 